\title{
An Econometric Analysis of Impact of Public Expenditure on Industrial Growth in Nigeria
}

\author{
Fatukasi A. Adebayo ${ }^{1}$, Adebisi T. Adebusuyi ${ }^{2} \&$ Mamidu A. Ishola $^{3}$ \\ ${ }^{1}$ Department of Economics, Adekunle Ajasin University, Akungba-Akoko, Ondo State, Nigeria \\ ${ }^{2}$ Department of Economics, Kingston University, Kingston on Thames, United Kingdom \\ ${ }^{3}$ College of Social and Management Sciences (COSMAS), Achievers University, Owo, Ondo State, Nigeria \\ Correspondence: Adebisi T. Adebusuyi, Department of Economics, Faculty of Art and Social Sciences, Kingston \\ University, Pr EM3004, Penrhyn Rd, Kingston on Thames, Surrey KT1 2EE, United Kingdom. Tel: \\ 44-74-6688-8984. E-mail: adebisiedun@gmail.com
}

Received: July 16, 2014

Accepted: July 31, 2014

Online Published: September 25, 2014

doi:10.5539/ijef.v6n10p112

URL: http://dx.doi.org/10.5539/ijef.v6n10p112

\begin{abstract}
The study empirically investigates the relationship between all public expenditures and industrial growth in Nigeria between the periods of 1970-2012. The dependent variables used is index of industrial productivity which serves as a proxy for industrial growth while the explanatory variables are government expenditure on Administration, economic services, social and community services, and transfers. The findings of the co-integration result reveal a long run relationship between industrial growth and government expenditure components. However, the estimated results reveal that government expenditure on administration, economic services, and transfers maintain a negative long run relationship with industrial growth in Nigeria while government expenditure on social and community services maintain a positive long run relationship. The Granger causality test shows that there exist no directional causality between government expenditure components and industrial growth in Nigeria in two lag periods. The study therefore serves as a pointer to the policy makers that there is need to accelerate industrial growth by changing the productive content of public expenditure in Nigeria.
\end{abstract}

Keywords: industrial growth, federal budget, economic services, budgetary expenditure

\section{Introduction}

One of the highly world debated economic issues is that whether increased government expenditure will strengthen the economy or not. Public expenditure can be termed as government expenditure on goods and services in order to keep the state moving. It covers federal government expenditure, state expenditure, local government and also extra budgetary expenditure. We will limit ourselves to the federal budget for purpose of this study.

Government is expected-to provide extension and services and infrastructural facilities, which will stimulate investment and augment the productive capacity of the economy. Economic policy formulations in Nigeria are geared towards achieving national development objectives and strategies. In a nutshell, the overall government objectives are those creating job opportunities and eradicating poverty and income disparities (Ogunleye \& Olorunfemi, 2006). Expenditure on administration include General Administration, National Assembly, Defense, Internal Security, Economy i.e. services which include agriculture, construction, transport and communication, and others, social and community service, include Education, Health and others. Transfer covers public debt charges, internal and external transfer, grants and pension.

The principal aim of this paper is to empirically evaluate the relationship between all public expenditures and industrial growth in Nigeria for the periods under review. For the purpose of analysis, we specifically analyze the trends of Nigerian government expenditure over the years and examine the nature of causality among index of industrial production and government expenditure on administration and economic services using the Granger causality test. The study hypothesizes that there is no significant relationship between public expenditure and industrial growth in Nigeria. To the knowledge of the authors, only few studies has been done on the subject matter of government expenditure and industrial growth especially in the developing countries (Nigeria).

The rest of the paper is structured in five sections. Following this introduction, in section two we consider a few 
selected relevant literature to public expenditure and industrial growth. Section three contains the methodologies used for the study. Section four discusses and analyzes the econometric result while section five concludes the study.

\section{Review of Relevant Literature}

Two major theories abound in public finance on the subject of public expenditure and growth of economy. The Keynesian school of thoughts' analysis centers on the role of government in economic growth while the Wagner's Law of public expenditure stressed that economic growth is the main determinant of public sector growth. Based on these, some studies on developing economies has found significant positive relationship between economic growth and the public sector growth and negative or no relationship for the developed economies.

There are number of papers that surveyed the existing literature on public expenditure. Musgrave and Musgrave (1984) examined public expenditure in the U.S.A between 1880 and 1900 and their outcome was that; public expenditure in absolute term was shown to have increased by multiple of 1,086 within this period. Using World Bank data, Barro (1988) found that government consumption and public investments relate' to industrial growth as it was predicted by his theoretical model. However, the effect of expenditures on education which was viewed by Barro as a proxy for investment in human was found to be insignificant.

Using the input-output model with consumption functions connected over the period 1959 to 1965 in Finland, Osmo (2010) evaluates the repercussions of public expenditure as well as examines the effects of public expenditure by industry. He finds that public expenditure has the smallest role among the final demand categories examined.

Ogunleye and Olorunfemi (2006), used co-integration analysis to test the long run relationship between public expenditures and industrial growth in Nigeria. The empirical results show that there is a long run positive relationship between GDP and total government expenditures with an R-squared of 0.748 . Aside using more recent data, this study will also employ both cointegration test and the Granger causality test to investigate the relationship between all public expenditures and industrial growth in Nigeria between the periods of 1970-2012.

\section{Methodology}

The time series data used for this study were mainly from publication of Central Bank of Nigeria, such as data on Industrial Productivity Index) (IPI), Government Expenditure on General Administration (GEA), Government Expenditure on Economic Services (GEE), Government Expenditure on Transfer (GET) and Government Expenditure on Social Services (GES).

A number of techniques can be used in such empirical work; the type of analytical techniques that is employed in this study is descriptive and comparative analyses. Based on the structure of the Nigerian economy and the available data, we employ the work of Barro (1998) and modified it as shown in the preceding sections.

\subsection{Model Specification}

Following the work of Barro (1988), the model for the study is specified as follows;

$$
\begin{gathered}
I P I=\alpha_{0}+\alpha_{1} T G E+\mu_{1} \\
I P I=\beta_{0}+\beta_{1} G E A+\beta_{2} G E E+\beta_{3} G E S+\beta_{4} G E T+\mu_{2}
\end{gathered}
$$

Where

IPI = Industrial Productivity Index;

$\mathrm{TGE}=$ Total Government Expenditure;

GEA $=$ Government Expenditure on General Administration;

GEE $=$ Government Expenditure on Economic Services;

GES = Government Expenditure on Social and Community Services;

GET $=$ Government Expenditure on Transfer;

$\alpha_{0}, \alpha_{1}, \beta_{0}, \beta_{1}, \beta_{2}, \beta_{3}$ and $\beta_{4}$ are parameters to estimate;

$\mu_{1}$ and $\mu_{2}$ are errors terms.

\subsection{Estimation Techniques}

In order to analyze the time series relationship of the variables used, we first test the stationarity properties of the variables by using Augmented Dickey Fuller (ADF) and Phillips-Perron (PP) tests of unit root. We also test the co-integration of the variable and the error correction. Thirdly, we test the causality between industrial productivity 
growth, government expenditure and its functional classification. Based on World's theorem, a stationary time series with no deterministic components has an infinite moving average representation (MA( $\infty)$ ) that can be approximated by a finite process. If non stationary series $(\mathrm{x})$ needs to be differenced ' $\mathrm{d}$ ' times until reaching stationary the time series is said to be integrated of order $d$, denoted by $X_{i} \sim I(d)$.

According to Engle and Granger methodology, the first step is to examine whether the time series contained in the equation has a unit root. In the co-integration literature, the more frequently used tests for a unit root are the Dickey-Fuller (1979 and 1981) and Phillips-Perron (1988). The tests agreed in their treatment to the intercept parameter.

Thus, the Null hypothesis model to test for units root has the following forms:

$$
\begin{gathered}
X_{t}+\mu+{ }_{a} X_{t^{-}-1}+e_{t} \\
X_{t}+\mu+\beta(t-T / 2)+{ }_{a} X_{t-1}+e_{t}
\end{gathered}
$$

Where $\mathrm{X}_{\mathrm{t}}$ is the logarithm of the time series and under the null hypothesis: $\mathrm{a}=1$ and $\beta=0$.

T represents the number of observations.

The maximum likelihood procedure suggested by Johansen (1988 and 1991) is particularly preferable when the number of variables in the study exceeds two due to the possibility of existence of multiple co-integrating vectors. The advantage of Johansen's test is not only limited to multivariate case, but is also preferable than Engle-Granger approach even with a two-variable model.

To determine the number of co-integrating vectors, Johansen (1988 and 1991) and Johansen and Juselius (1990) suggested two statistic tests. The first one is the trace test (Xtrace). It tests the null hypothesis that the number of distinct co-integrating vectors is less than or equal to $(\mathrm{q})$, against a general unrestricted alternative (q-r). The second statistical test is the maximal eigen-value test (Xmax). This test concerns a test of the null hypothesis that there is $(r)$ of co-integrating vectors against the alternative that there is $(r+1)$ of co-integrating vectors.

Granger causality test is a technique for determining whether one time series is useful in forecasting another (Granger, 1969). Ordinarily, regression reflects 'mere' correlation, but Clive Granger argued that there is an interpretation of a set test as revealing something about causality. A times series $\mathrm{X}$ is said to Granger-causer $\mathrm{Y}$ if it can be shown, usually through a series of F-tests on lagged values of X (and with lagged valves of Y also know), that those values provide statistically significant information about future values of $Y$.

Despite its name, Granger causality does not imply true causality. If both $\mathrm{X}$ and $\mathrm{Y}$ are driven a common third process with different lags, their measure of Granger causality could still be statistically significant. Yet manipulation of one process would not change the other. Indeed, the Granger test is designed to handle pairs variables and may produce misleading results when the true relationship involves three or more variable.

\section{Discussion of Empirical Results}

As earlier stated that the main objective of this research work is to empirically investigate the relationship between public expenditure and industrial growth in Nigeria, this section therefore concentrates on the presentation of time series data used, followed by the descriptive analysis, interpretation of the unit root tests, co-integration analysis, error correction mechanism, and Granger causality test.

\subsection{Descriptive Analysis of Data}

Table 1. Descriptive statistics of the data

\begin{tabular}{llllll}
\hline Variables & IPI & GEA & GEE & GES & GET \\
\hline Means & 116.002 & $117,813.951$ & $86,269.343$ & $49,708.157$ & $132,758.206$ \\
Maximum & 162.387 & $920,400.039$ & $483,100.022$ & $378,500.404$ & $620,420.459$ \\
Minimum & 41.344 & 109.284 & 46.577 & 4.288 & 567.766 \\
STD.Deviation & 30.787 & $222,855.155$ & $134,145.865$ & $9,120,705.375$ & $197,807.173$ \\
\hline
\end{tabular}

Table 1 presents the descriptive statistics of the data used in the empirical analysis. The industrial productivity index (IPI) averaged 116.002 between 1970 and 2007 and varied from a minimum of 41.344 in 1970 to a Maximum of 162.387 in 2007. Government expenditure on administration (GEA) also averaged 117,813.951 and varied from a minimum of 109.284 in 1971 to a maximum of 920,400.039 in 2007. Government expenditure on economic services (GEE) average 86,269.343 and varied from a minimum of 46.577 in 1970 to a maximum of 
$483,100.022$ in 2007 . The average of government expenditure on social services (GES) is almost half of GEE with a value of 49,708.157 and varied from minimum of 4.288 in 1970 to maximum of 378,500.404 in 2007. The highest average is recorded by government expenditure on transfers (GET) with a value of 132,758.206. GET varied from a minimum value of 567.766 in 1973 to a maximum of 620,420.459 in 2012 .

\subsection{Time Series Properties of the Variables}

In order to avoid the problem of spurious regression, we begin by examining the time series properties of the variables. In literature, most economic time series are non-stationary and including non-stationary variables in the models can lead to spurious regression co-efficient estimate (Granger \& New bold, 1977).

\subsection{Unit Root Test Result}

The unit root test is conducted to determine whether the variables are stationary and to determine the order of integration of the variables using the Augmented Dickey-Fuller (ADF) test. This is the first step in the three-stage test of unit root, co integration and error correction model.

Table 2. Augmented Dickey-Fuller test result at first difference

\begin{tabular}{cccc}
\hline Variable & Adf Statistic & Critical Value $@ \mathbf{5 \%}$ & Order of Intergration \\
\hline IPI & -4.542 & -2.947 & $\mathrm{I}(1)$ \\
GEA & -4.525 & -2.947 & $\mathrm{I}(1)$ \\
GEE & -4.439 & -2.947 & $\mathrm{I}(1)$ \\
GES & -6.351 & -2.949 & $\mathrm{I}(2)$ \\
GET & -4.304 & -2.947 & $\mathrm{I}(1)$ \\
\hline
\end{tabular}

Table 2 shows the result of the Augmented Dickey-Fuller test. The test indicates that none of the variables were stationary at level. However, to ensure their stationarity, they were all differenced once except for GES that was difference twice to arrive at stationary. This means that IPI, GEA, GEE, and GET are integrated of order one while GES is integrated of order two. Therefore, the variables do not contain a unit root.

The normalized co-integrating coefficient with the highest log-like hood ratio is chosen as the long run equilibrium equation.

$$
I P I=16,471.651-0.060 G E A-0.013 G E E+0.022 G E S-0.084 G E T
$$

The equation above represents the long run equilibrium equation. It shows that GEA, GEE, and GET maintained a negative long run relationship with IPI in Nigeria. GEA in the long run will pull down IPI by $0.060 \%$. Also, GEE and GET will pull down the long run by $0.013 \%$ and $0.084 \%$ respectively. On the other hand, GES maintained a positive long run relationship with IPI GES will pull up by $0.022 \%$ in the long run. Thus, IPI, GEA, GEE, GES GET co-integrate in the long run which means that industrial growth and public expenditure (functional components) maintained a long run relationship.

\subsection{Error Correction Model}

In other to capture the short run deviations that might have occurred in estimating the long run co-integrating equations, a dynamic error correction model is formulated. The error correction term ECM (-1) depicts the speed of convergence to equilibrium once the equation is shocked.

Table 3. Result of the error correction model

\begin{tabular}{lccc}
\hline VARIABLE & CO-EFFICIENT & STD-ERROR & P-VALUE \\
\hline CONSTANT & 3.651 & 2.793 & 0.206 \\
D (IPI (-1) & -0.102 & 0.216 & 0.641 \\
D (IPI(-2) & 0.011 & 0.209 & 0.957 \\
D (GEA) & -0.000 & 0.000 & 0.980 \\
D (GEA(1) & -0.000 & 0.000 & 0.817 \\
D(GEA(-2) & 0.000 & 0.000 & 0.916 \\
D (GEE(-1) & 0.000 & 0.000 & 0.820 \\
D (GEE( ) $)$ & 0.000 & 0,000 & 0.815 \\
D (GEE(-2) & -0.000 & 0.000 & 0.768 \\
D (GES) & -0.000 & 0.000 & 0.543 \\
\hline
\end{tabular}




\begin{tabular}{lccc}
\hline $\mathrm{D}(\mathrm{GES}(1)$ & 0.000 & 0.000 & 0.822 \\
$\mathrm{D}(\mathrm{GES}(2)$ & 0.000 & 0.000 & 0.895 \\
$\mathrm{D}(\mathrm{GET})$ & -0.000 & 0.000 & 0.617 \\
$\mathrm{D}(\mathrm{GET}(1)$ & 0.000 & 0.000 & 0.862 \\
$\mathrm{D}(\mathrm{GET}(-2)$ & 0.000 & 0.000 & 0.705 \\
ECM(-1) & -0.211 & 0.115 & 0.082 \\
R-squared=0.245 & & & \\
\hline
\end{tabular}

Table 3 shows that ECM (-1) co-efficient is -0.211 (negative as expected). This means that $21.116 \%$ of the disequilibrium will be corrected in each period. The probability value $(8.270 \%<10 \%)$ of ECM $(-1)$ coefficient confirms its statistical significance.

Also, one period lagged IPI, present and one period lagged GEA, two lagged period GEE, present GES and present GET are negatively related to IPI. On the other hand, two period lagged IPI, two period lagged GES, one period lagged GEE, one and two period lagged GET are positively related to IPI. R-squared of the model is 0.245. Although this value is low but it is warranted based on the nature of the variables in the model. There are so many other variables that IPI depends on which are deliberately not included in the model. There exclusion was aimed at concentrating on public expenditure impact on industrial productivity.

\subsection{Granger Causality Test}

The Granger causality test was carried out to determine the existence and direction of causality between IPI and GEA, IPI and GEE, IPI and GES, IPI and GET, IPI and RGE (Recurrent government expenditure), IPI and CGE (Capital government expenditure) and IPI and TGE (Total government expenditure). To achieve this, three different models were used.

$$
\begin{gathered}
I P I=f(G E E, G E S, G E A, G E T) \\
I P I=f(C G E, T G E) \\
I P I=f(R G E, T G E)
\end{gathered}
$$

On the long run, government expenditure on general administrative is negatively related to the industrial productivity in Nigeria. This is to confirm that those who do not consume locally made products are generally involved in financial crimes like embezzlement and corrupt practices in the country and thereby reduce effective demand of industrial products.

The relationship of industrial performance and government expenditure on economic services in Nigeria is also negative. This is unexpected as we would expect a strong positive relationship between the two variables. The result actually conforms with the economic situation experienced in Nigeria today.

The relationship between government expenditure on transfer and industrial productivity is also negative in the long in Nigeria. This however, conforms with economic theory on the ground that there is no corresponding productive activity for this kind of expenditure. Out of all the four functional components of Government expenditure, only Government expenditure on social services has a positive impact on economic growth. This means that if Government can improve on these facilities, industrial productivity will experience positive increase.

The Ganger causality tests reveal a surprising relationship between public expenditure component and industrial growth. The test shows that there is no causality of any form existing between these set of variables. This means that all the millions and billions in various fiscal years has not by any means lead to industrial growth in Nigeria. This is however should not be surprising in a country ravaged by a coma state of power supply, bad road and poor transportation system, high rate of financial corruption, capital flight, poor social amenities and white elephant projects.

\section{Conclusion and Recommendation}

The study aimed at an empirical investigation of the relationship between all public expenditure and industrial growth in Nigeria between the reviewed periods.

The dependent variable used was industrial growth using index of industrial productivity while the explanatory variables are government expenditure on Administration, economic services, social services and transfer.

Co-integration, error-correction mechanism, and Granger causality test were adopted as the estimation technique. The co-integration result revealed a long run relationship existing between industrial growth and total government expenditure components. However, the estimated results revealed that government expenditure on administration, 
economic services, and transfers maintained a negative long run relationship with industrial growth in Nigeria while government expenditure on social services maintained a positive long run relationship.

The Granger causality test shows that there exist no directional causality between total government expenditure components and industrial growth in Nigeria in two lags period.

The study therefore serves as a pointer to the fact that policy makers have the responsibility to accelerate industrial growth by enhancing the productive content of public expenditure in Nigeria.

From the empirical results, it is shown that the long run relationship between government expenditure and industrial growth varies among the components of public expenditure but was positive between total government expenditure and industrial growth. It can therefore be seen that there is no crowding out effect. However, all hands must be on deck to improve the growth of industrial sector in Nigeria.

The low R-squared of about $25 \%$ signifies that there are lots of other factors apart from government expenditure responsible for industrial growth in Nigeria. These factors include electricity, interest rate, exchange rate, political stability, corruption to mention few. It is therefore pertinent for policy makers to pay more attention to these factors so as to augment public expenditure on the path of improving industrial growth. Nevertheless, high growth of industrial productivity is far from reality if public expenditure is not directed towards productive channels.

\section{Acknowledgment}

The authors acknowledge the personal efforts put into the manuscript preparation by Mr. Adebowale T. Adebusuyi.

\section{References}

Barro, R., (1988). Economic Growth in a Cross-section of Countries. Quarterly Journal of Economics, 106(2), 407-443. http://dx.doi.org/10.2307/2937943

Dickey, D. A., \& Fuller, W. A. (1979). Distribution of the Estimators for Autoregressive Time Series with a Unit Root. Journal of the American Statistical Association, 74, 427-431.

Dickey, D. A., \& Fuller, W. A. (1981). Likelihood Ratio statistics for Autoregressive Time Series with a Unit Root. Econometrica, 49, 1057-1072. http://dx.doi.org/10.2307/1912517

Granger, C. W. J. (1969). Investigating causal relations by econometrical models and cross-spectral methods. Econometrica, 37(3), 424-438. http://dx.doi.org/10.2307/1912791

Granger, C. W. J., \& Newbold, P. (1977). Forecasting economic time series (pp. 333). New York: Academic Press.

Johansen, S. (1988). Statistical Analysis of Cointegration Vectors. Journal of Economic Dynamics and Control, 12, 231-254. http://dx.doi.org/10.1016/0165-1889(88)90041-3

Johansen, S. (1991). Estimation and Hypothesis Testing of Cointegration Vectors in Gaussian Vector Autoregressive Models. Econometrica, 59, 1551-1580. http://dx.doi.org/10.2307/2938278

Johansen, S., \& Juselius, K. (1990). Maximum Likelihood Estimation and Inference on Cointegration-with Applications to the Demand for Money. Oxford Bulletin of Economics and Statistics, 52, 169-210. http://dx.doi.org/10.1111/j.1468-0084.1990.mp52002003.x

Musgrave, R. A., \& Musgrave, P. B. (1984). Public Finance in Theory and Practice (4th ed., pp.7-12). New York: McGraw-Hill.

Ogunleye, E. O., \& Olorunfemi, S. (2006). Public expenditure and economic in Nigeria: A cointegration analysis. Journal of Economic and Social Studies, 5, 1596-4256.

Osmo, F. (2010). Effects of Public Expenditure on Production, Incomes and Employment in Finland. Unpublished paper, University of Oulu, Finland.

Phillips, P. C. B., \& Perron, P. (1988). Testing for a Unit Root in Time Series Regression. Biometrika, 75, 335-346. http://dx.doi.org/10.1093/biomet/75.2.335

\section{Copyrights}

Copyright for this article is retained by the author(s), with first publication rights granted to the journal.

This is an open-access article distributed under the terms and conditions of the Creative Commons Attribution license (http://creativecommons.org/licenses/by/3.0/). 